\title{
Prospective Evaluation of Early Complications After Elective Loop lleostomy: Need to Optimise Loperamide Management?
}

\author{
Bolckmans Roel $^{1}\left({ }^{10} \cdot\right.$ Cornille Jean-Baptiste $^{2} \cdot$ Singh Sandeep $^{1} \cdot$ Boyce Stephen $^{1} \cdot$ D $^{\prime}$ hoore André $^{2} \cdot$ Wolthuis Albert $^{2}$
}

Received: 19 June 2021 / Accepted: 3 September 2021 / Published online: 24 September 2021

(c) The Author(s) 2021

Keywords Loop ileostomy $\cdot$ Complications $\cdot$ Readmissions $\cdot$ Stoma output $\cdot$ Loperamide

\section{Introduction}

The need for a standard diverting ileostomy during "low" colorectal resections is continuously questioned because of increased awareness of the associated morbidity, with a move towards a "selective" use and close postoperative follow-up (FU). ${ }^{1}$

Most data in literature regarding ileostomy-related complication originates from studies with a retrospective design, with its known associated weaknesses of data incompleteness and lack of detailed recording. ${ }^{2}$ The aim of our study was to assess loop ileostomy-related complications in a prospective way, with focus on ileostomy output.

\section{Materials and Methods}

Prospective data collection between October 2017 and August 2018 in two high volume colorectal centres. All patients who underwent an elective loop ileostomy formation were included.

Distance from the ileocecal valve and surgical technique was applied as per surgeons' preference, and loperamide management was not standardised. All FU data were recorded during in-person clinic visits. Photographs were taken of patients' loop ileostomy after their written consent at standardised time points during the study, to reassure an objective assessment over the two centres.

Bolckmans Roel

roel_bolckmans@hotmail.com

1 Department of Colorectal Surgery, NIHR Oxford Biomedical Research Centre, Oxford University Hospitals NHS Foundation Trust, Oxford, UK

2 Department of Colorectal Surgery, University Hospital Gasthuisberg, Leuven, Belgium
Means \pm standard deviation or median with interquartile range was used according to distribution, T-test, or Mann-Whitney U test to compare numerical data and Chisquare or Fisher's exact for categorical data. $P \leq 0.05$ was considered as the significance level.

\section{Results}

Mean hospital stay of the 81 included patients was $11 \pm 9$ days. None of the patients had a history of/or concomitant small bowel resection.

No ileostomy-related reinterventions were recorded during admission. Mean stoma output at discharge was $696 \pm 412 \mathrm{ml} /$ day, with $27 / 81$ (33\%) being on loperamide (Table 1). Twenty-six patients (32\%) had an high output stoma (HOS, $\geq 1500 \mathrm{ml} /$ day) during admission, with a significantly higher mean stoma output of $854 \pm 386 \mathrm{ml} /$ day at time of discharge $(p=0.03)$. There was a delay in discharge due to stoma-related issues in 17 patients $(21 \%)$; because of HOS in 9 and stoma care in 8 patients (stoma training/ application problems).

At 3-month FU, 79\% reported nocturnal emptying with $36 \%$ of them being on loperamide therapy, $36 \%$ experienced stoma bag leaks.

Two patients $(2.5 \%)$ had an early ileostomy closure because of related morbidity (stoma bag leaks, peristomal fistula).

There were 12 readmissions in 8 patients $(10 \%)$ because of ileostomy-related complications, with in $4 / 8$ patients (50\%) because of ileostomy output-related complications and need for intensive care unit admission in one patient within a week after discharge (stoma output at discharge $975 \mathrm{ml} /$ day) (Table 1). 
Table 1 Ileostomy complications during admission, 1-month and 3-month clinical follow-up

\begin{tabular}{|c|c|c|c|}
\hline & Admission $(N=81)$ & One-month $(56 / 74(76 \%))^{a}$ & Three-month $(53 / 69(77 \%))^{b}$ \\
\hline Daily loperamide N (\%) & $27(33)$ & $13(23)$ & $16(30)$ \\
\hline Stoma output (median number of emptied stoma bags a day) & (f) & 5 (IQR 4-6) & 5 (IQR 4-6) \\
\hline Necrosis $N(\%)^{c}$ & $3(4)$ & NA & NA \\
\hline Hematoma with clinical impact ${ }^{\mathrm{d}} \mathrm{N}(\%)$ & $0(0)$ & NA & NA \\
\hline Peristomal abscess/cellulitis $\mathrm{N}^{\mathrm{e}}(\%)$ & $2(3)$ & $0(0)$ & $0(0)$ \\
\hline Nocturnal emptying N (\%) & NA & $40(71)$ & $42(79)$ \\
\hline Dermatitis N (\%) & NA & $20(36)$ & $10(19)$ \\
\hline Mucocutaneous separation N (\%) & $3(4)$ & $4(7)$ & $0(0)$ \\
\hline $\begin{array}{l}\text { Retraction stoma N (\%) } \\
\text { Flush N (\%) }\end{array}$ & $\begin{array}{l}2(2) \\
4(5)\end{array}$ & $\begin{array}{l}5(9) \\
6(11)\end{array}$ & $\begin{array}{l}1(2) \\
9(17)\end{array}$ \\
\hline $\begin{array}{l}\text { Stoma bag leaks } N(\%) \\
\text { If a leak, the median number of stoma bag leaks }\end{array}$ & $\begin{array}{l}31(38) \\
2(\text { IQR } 1-3)\end{array}$ & $\begin{array}{l}20(36) \\
1(\text { IQR } 1-5)\end{array}$ & $\begin{array}{l}19(36) \\
1(\text { IQR } 1-2)\end{array}$ \\
\hline Number of Readmissions & NA & $\begin{array}{l}\text {-HOS: } 2 \\
\text {-LOS: } 3 \\
\text {-Loperamide: } 1 \\
\text {-(Sub)obstruction: } 2 \\
\text {-Parastomal infection: } 1\end{array}$ & $\begin{array}{l}\text {-HOS: } 1 \\
\text {-LOS: } 3 \\
\text {-(Sub)obstruction: } 3 \\
\text {-Stoma bleeding: } 2\end{array}$ \\
\hline
\end{tabular}

$N$ number of patients, IQR interquartile range, $N A$ not applicable, HOS high output stoma, LOS low output stoma

Admission data were evaluated and reported at the time of discharge

${ }^{a} 75$ patients hospital stay $<4$ weeks with one patient deceased 3 weeks after surgery (subarachnoid bleeding)

${ }^{\mathrm{b}} 69$ patients still alive and not reversed three months after index surgery

${ }^{c}$ Defined as the necrotic appearance of ileostomy mucosa (all managed successfully conservatively, no need for reintervention, BMI patients 23.3 / 26.4 / 30.6)

${ }^{\mathrm{d}}$ Two patients on therapeutic anticoagulation before surgery who didn't experience postoperative hematoma

${ }^{\mathrm{e}}$ Defined as the need for antibiotic therapy for peristomal cellulitis

${ }_{\mathrm{f}}^{\mathrm{f}}$ Detailed recording in $\mathrm{ml} /$ day

Median loperamide dose after 1 month $5 \mathrm{mg}$ (3-8), after 3 months $6 \mathrm{mg}$ (4-12)

Admission data were evaluated and reported at the time of discharge

\section{Discussion}

HOS-related complications together with postoperative ileus/obstruction and deep infections are seen as the main reasons for readmission after elective colorectal surgery. ${ }^{3}$ The results of our study confirm that morbidity related to the first factor is significant, with HOS-related readmission in three patients (4\%) and need for intensive care unit admission in one of them within 1 week after discharge. Additionally, 9 patients (11\%) experienced a delay in discharge during elective admission because of HOS which is a known risk factor for readmission. ${ }^{4}$

With those observations in mind, our centres put forward a flowchart to aim for consistent stoma output management during admission and discharge with a focus on loperamide therapy [Fig. 1]. In our opinion, this will result in a more systematic approach in ileostomy output management.

The importance of careful management of patients' ileostomy output is further supported by a possible impact on their long-term kidney function. ${ }^{5}$

Strength of our study is the prospective design which allowed a detailed assessment of the ileostomy-related measures and a weakness the limited number of patients.

Further research has to focus on the question if more consistent use of loperamide therapy during admission and FU can further reduce readmission rates and morbidity associated with ileostomy formation. 
Fig. 1 Inpatient flowchart

\section{Inpatient flowchart for loperamide management}

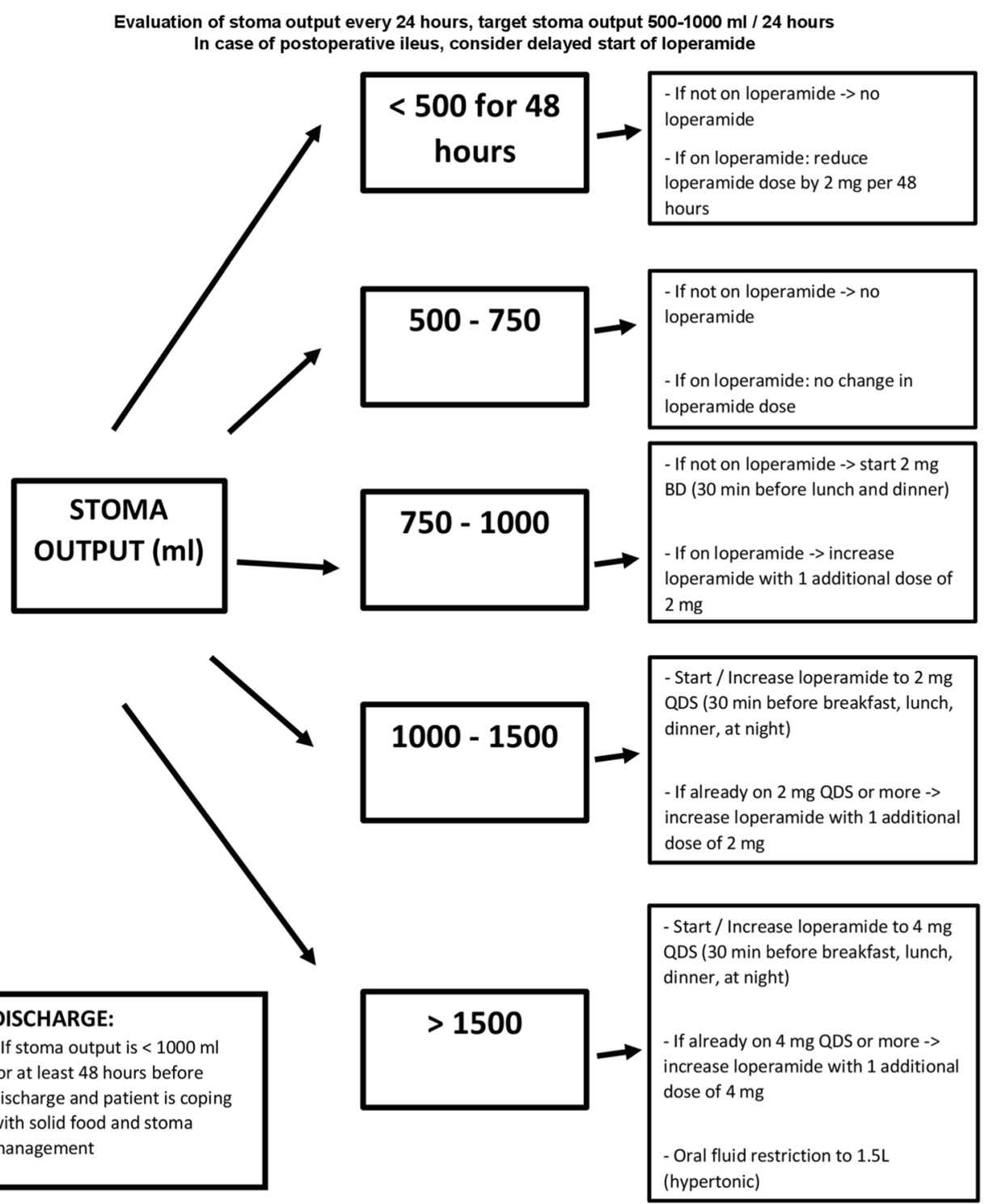

Acknowledgements We thank all the member of the stoma teams in Oxford University Hospitals NHS Foundation Trust and University Hospital Gasthuisberg for their hard work and participation in this study. Additionally, we thank Renato Roriz-Silva for his contribution to the statistical analysis of the study data.

Authors' Contribution All authors participated sufficiently in the work as per guidelines of the International Committee of Medical Journal Editors.

\section{Declarations}

\section{Conflict of Interest None declared}

Open Access This article is licensed under a Creative Commons Attribution 4.0 International License, which permits use, sharing, adaptation, distribution and reproduction in any medium or format, as long as you give appropriate credit to the original author(s) and the source, provide a link to the Creative Commons licence, and indicate if changes were made. The images or other third party material in this article are included in the article's Creative Commons licence, unless indicated otherwise in a credit line to the material. If material is not included in the article's Creative Commons licence and your intended use is not permitted by statutory regulation or exceeds the permitted use, you will need to obtain permission directly from the copyright holder. To view a copy of this licence, visit http://creativecommons. org/licenses/by/4.0/.

\section{References}

1. Blok, R.D., Stam, R., Westerduin, E., Borstlap, W.A.A., Hompes, R., Bemelman, W.A., Tanis, P.J. Impact of an institutional change from routine to highly selective diversion of a low anastomosis after TME for rectal cancer. Eur J Surg Oncol 2018, 44(8):1220-1225. 
2. Ihnat, P., Gunkova, P., Peteja, M., Vavra, P., Pelikan, A., Zonca, P. Diverting ileostomy in laparoscopic rectal cancer surgery: high price of protection. Surg Endosc 2016, 30(11):4809-4816

3. Grass, F., Crippa, J., Lovely, J.K., Ansell, J., Behm, K.T., Achilli, P., Hubner, M., Kelly, S.R., Mathis, K.L., Dozois, E.J., Larson, D.W. Readmissions within 48 hours of discharge: Reasons, risk factors, and potential improvements. Dis Colon Rectum 2020, 63(8):1142-1150

4. Paquette, I.M., Solan, P., Rafferty, J.F., Ferguson, M.A., Davis, B.R. Readmission for dehydration or renal failure after ileostomy creation. Dis Colon Rectum 2013, 56(8):974-979
5. Fielding, A., Woods, R., Moosvi, S.R., Wharton, R.Q., Speakman, C.T.M., Kapur, S., Shaikh, I., Hernon, J.M., Lines, S.W., Stearns, A.T. Renal impairment after ileostomy formation: a frequent event with long-term consequences. Colorectal Dis 2020, 22(3):269-78

Publisher's Note Springer Nature remains neutral with regard to jurisdictional claims in published maps and institutional affiliations. 